\title{
General Psychiatry Assessing the severity of methamphetamine use disorder beyond the subjective craving report: the role of an attention bias test
}

Qiongdan Liang, ${ }^{1,2}$ Tifei Yuan, ${ }^{3}$ Xinyu Cao, ${ }^{4} \mathrm{Hao} \mathrm{He},{ }^{4}$ Jiemin Yang, ${ }^{1}$ Jiajin Yuan ${ }^{1}$

To cite: Liang Q, Yuan T, Cao X, et al. Assessing the severity of methamphetamine use disorder beyond the subjective craving report: the role of an attention bias test. General Psychiatry 2019;32:e100019. doi:10.1136/ gpsych-2018-100019

Received 08 October 2018 Revised 20 December 2018 Accepted 24 December 2018

Check for updates

(c) Author(s) (or their employer(s)) 2019. Re-use permitted under CC BY-NC. No commercial re-use. See rights and permissions. Published by BMJ.

${ }^{1}$ The Laboratory for Affect Cognition and Regulation (ACRLab), Key Laboratory of Cognition and Personality of Ministry of Education (SWU), Faculty of Psychology, Southwest University, Chongqing, China

${ }^{2}$ Department of Psychology,

Tsinghua University, Beijing,

China

${ }^{3}$ Shanghai Mental Health Center, Shanghai Jiaotong University,

Shanghai, China

${ }^{4}$ Da Lian Shan Institute of Addiction Rehabilitation, Nanjing, China

Correspondence to Dr Jiajin Yuan; yuanjiajin168@126.com; yuanjiaj@swu.edu.cn

\section{ABSTRACT}

Background Methamphetamine (MA) is one of the most commonly abused illicit psychostimulant drugs and MA use disorder constitutes a universal health concern across the world. Despite many intervention approaches to MA use disorder, the indicator of addiction severity is mainly limited to subjective craving score to drug-related cues, which is influenced by many factors such as social approval and self-masking.

Aim The present study investigates whether self-reported craving for drug use in response to MA cues is a reliable indicator for addiction severity in MA users, and then tests the validity of the cue-induced attention bias test in addiction severity assessment

Methods Fifty-two male MA users completed the cueinduced craving test and attention bias task, and were required to report clinical characteristics of addiction severity. For the attention bias test, subjects were required to discriminate the letter superimposed onto MA userelated or neutral scenes. The reaction time delay during MA-use condition relative to neutral condition was used as an index of the attention bias.

Results The results showed that 24 of the 52 MA users rated non-zero in cue-induced craving test, and they showed a significant attention bias to drug-related pictures. However, the other 28 users who rated zero in cue-induced craving evaluation showed a similar attention bias to drug-related cues. In addition, the attention bias to MA use-related cues was significantly and positively correlated with the clinical indexes of addiction severity, but the relationship was absent between subjective craving evaluation and the indexes of addiction severity. Conclusion These results suggest that attention bias to MA cues may be a more reliable indicator than experiential craving report, especially when subjective craving is measured in the compulsory rehabilitation centre.

\section{INTRODUCTION}

Methamphetamine (MA) is one of the most commonly abused illicit psychostimulant drugs. ${ }^{1}$ MA user disorder is associated with paranoia, behavioural impulsivity and cognitive impairment. ${ }^{2}$ However, neither medication nor psychosocial treatment has been proven to effectively treat MA use disorder with regard to vulnerability for relapse. ${ }^{3} \mathrm{~A}$ number of factors are thought to contribute to relapse, including exposure to drug cues and addiction severity. ${ }^{4}$ Drug cues refer to things, people or situations that are associated with drug use, which may trigger drug seeking behavior. ${ }^{5}$ Despite many intervention approaches to MA use disorder, the indicator of addiction severity is mainly limited to the subjective craving score to drug-related cues, ${ }^{6}{ }^{7}$ which is obscured by many factors such as social approval and self-masking. ${ }^{8}$

Cognitive models, such as the expectancy model, the dual-affect model and the cognitive processing model, all hold that external environmental events serve as triggers for drug use. ${ }^{9}$ For an individual addicted to a specific substance, stimuli associated with that substance will automatically capture attention whereas this is not evident in normal subjects. It has been indicated that the attention bias (AB) towards drug-related cues has a predictive role for drug relapse ${ }^{10}$ and may be an important factor in predicting drug abuse treatment outcome. ${ }^{11}$ Attention bias for drug-related cues can be measured directly by monitoring eye movements, ${ }^{12}$ or indirectly inferred with reaction time or other indicators. ${ }^{13}{ }^{14}$ Indirect measures of attentional bias have largely made use of either of two tasks: the modified Stroop task and visual probe (dot-probe) task. ${ }^{1516}$ Attentional bias is indicated by faster reaction times to probes that replace drug-related images, which has been generally applied in tobacco, opiate and cocaine use disorder studies. However, few studies have focused on the attention bias of methamphetamine users. ${ }^{11}$ Although direct measurement of attention bias may be done using eye-tracking, simple measures may be preferred for practical purposes and ease of administration (such as the high cost of eye-tracking equipment). 
Furthermore, as subjects do not need to overtly assess how they are craving for drug use, the attention bias test should be independent of subjects' attitude towards MA use or sociocultural influences. Consideration of these potential obscuring factors is particularly important in assessing addiction severity in MA users, as MA use is illegal across the world. In this regard, attention bias to drug cues may be a more objective and sensitive index for addiction severity. Currently, we use a modified visual probe task, which employs attentional bias as an indicator, to test how attention bias to drug cues may predict addiction severity in MA users.

Specifically, this study directly compared the results of self-report craving and drug-related attention bias, and we examined whether self-reported craving for drug cues is a reliable index for the detection of addiction severity in subjects with a long history of MA use disorder, and then tested whether the severity of addiction can be more sensitively and reliably assessed by the cue-induced attention bias test.

\section{METHODS}

\section{Participants}

Fifty-two male individuals (aged 23-57 years, mean $=35.54$; $\mathrm{SD}=8.18$ years) from Nanjing Compulsory Rehabilitation Center who met the Diagnostic and Statistical Manual of Mental Disorders criteria for MA use disorder (mean (MA use history) $=4.55 ; \mathrm{SD}=2.72$ years) participated in this study. ${ }^{17}$ The inclusion criteria were (1) aged 20 to 60 years; (2) normal vision and hearing; (3) received no medications during treatment; (4) in compulsory abstinence from drug use for more than 1 month. The exclusion criteria were (1) serious physical or mental illness; (2) history of epilepsy. All the subjects participated in the study voluntarily.

The experimental procedure was in accordance with the ethical principles of the 1964 Declaration of Helsinki (World Medical Organization, 1996).

\section{Data collection and measurements}

Each subject completed a questionnaire (see figure 1), which included demographic characteristics and clinical characteristics of addiction severity involving MA use duration (years), maximum amount (g) and weekly amount $(\mathrm{g})$. All the subjects completed the visual probe task and the cue-induced subjective craving evaluation with an inter-task interval for 5 minutes. Visual probe task preceded cue-induced craving paradigm in order to avoid potential amplifying effects of attention bias by prolonged presentation of MA-use scenarios.

\section{Modified visual probe task}

We used a modified visual probe task to assess MA-related attention bias (see figure 2). The modified visual probe task consisted of 60 trials. Each trial started with a jittered fixation varying from 800 to $1200 \mathrm{~ms}$, which was followed by the presentation of task stimulus. The task stimuli
In 2016, 225 drug users in the Da Lian Shan Institute of Addiction Rehabilitation within 1 month were recruited between June and September.

113 drug users that took heroin and other type of drugs were excluded from the experiment.

72 subjects met Diagnostic and Statistical Manual of Mental Disorders (DSM-V) criteria for MA use disorders.

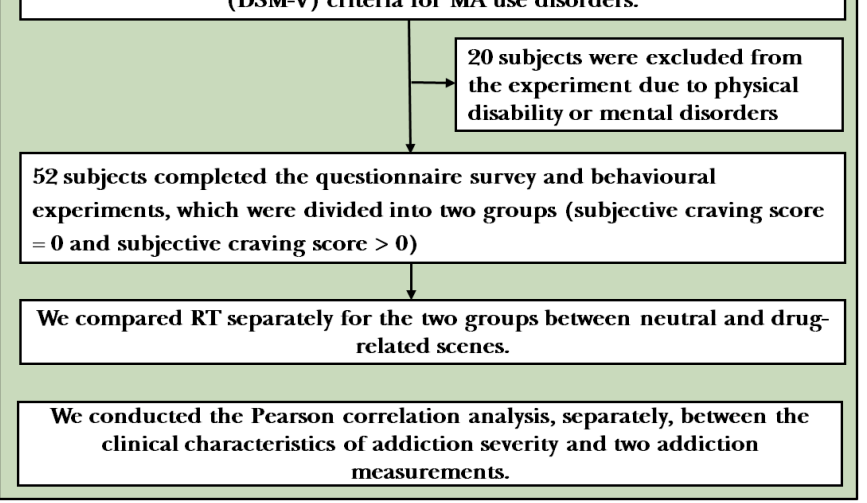

Figure 1 Flowchart of the study. MA, methamphetamine; $\mathrm{RT}$, reaction time.

contained 10 pictures (five neutral and five drug-related scenes) superimposed by a letter ( $\mathrm{W}$ or $\mathrm{M}$ ) in three different positions (top, centre, bottom). The two letters were presented with equal probability. The subjects were instructed to press ' 1 ' or ' 2 ' quickly and accurately for letter classification, regardless of the background picture. Attention bias to MA use relative to neutral scenes could be obtained by the reaction time delay between MA-related and neutral conditions.

\section{Cue-induced craving paradigm}

In the craving test, a block-wise method was used to continuously present six MA use-related pictures (eg, MA-intake utensils, tools and the scenarios of MA intake) for $24 \mathrm{~s}$ ( $4 \mathrm{~s}$ each). The six pictures used in the cue-induced craving paradigm were not presented in the visual probe task. Participants were instructed to pay close attention to the picture and rated their level of craving after watching these pictures. Craving was assessed by visual analogue scales (VAS), with 0 (not at all) to 100 (extremely intense).

\section{Data analysis}

Subjective craving for MA use was measured as the score obtained on the VAS (possible range: $0-100$ ). According to the subjective craving score, 52 subjects were divided into two groups (subjective craving score $=0$; subjective craving score $>0$ ), which signals diverse outcomes from subjective craving measurement.

As for the modified visual probe task, only the response time (reaction time; RT) on the correct trial was considered to be taken into the analyses of RT. RTs exceeding 3 SDs of the means of a given condition for a given participant were trimmed. We compared RT separately for the two groups (subjective craving score $=0$; subjective craving 


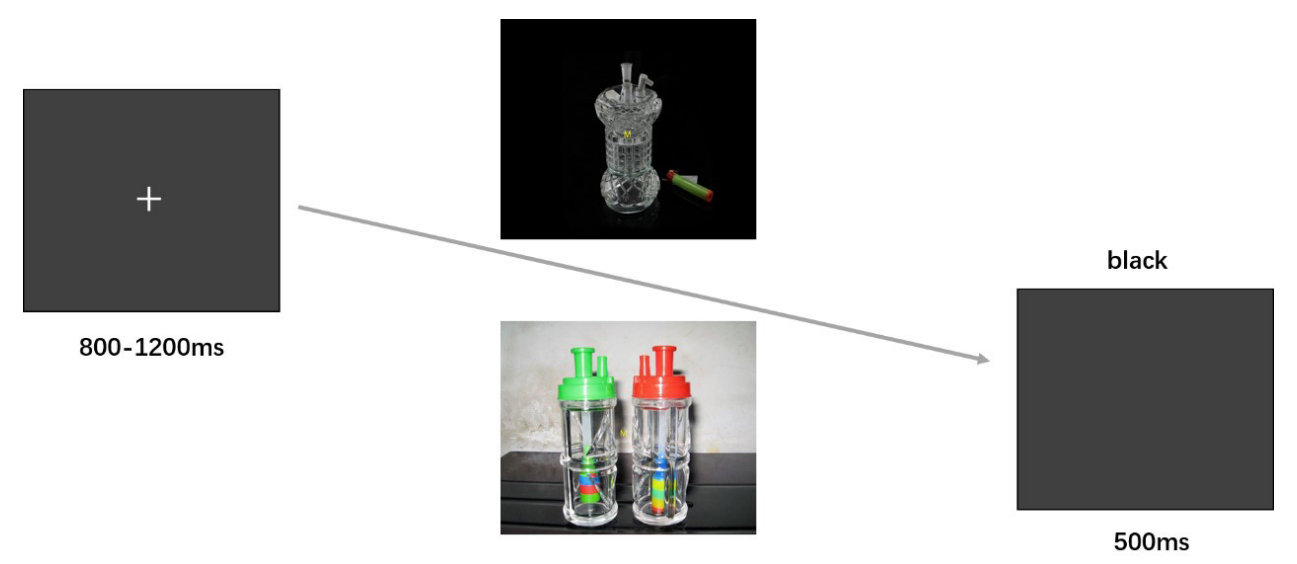

Figure 2 Behavioural procedure of the modified visual probe task.

score $>0$ ) between neutral and drug-related scenes to verify the consistency of results between attention bias and subjective craving methods.

In addition, to assess the relationship among addiction severity, subjective drug craving and drug-related attention bias, we conducted tests of Pearson correlations, separately, between the clinical characteristics of addiction severity (MA use duration (years), maximum amount (g) and weekly amount $(\mathrm{g})$ ) and the two addiction measurements (subjective craving and attention bias).

The data were presented as mean (SD), and statistical analysis was performed with SPSS V.16.0 software. Repeated measures analysis of variance (ANOVA) model was used and $\mathrm{p}$ value $<0.05$ was considered statistically significant. We used two-tailed $\mathrm{p}$ values for these comparisons.

\section{RESULTS}

Attention bias to drug-related situations in all subjects

Fifty-two MA users rated subjective craving score after exposure to drug-related scenes, among whom 28 users rated zero in the subjective craving scale (see figure $3 \mathrm{~A}$ ). Users who rated zero were not distinct from users who rated non-zero in age, impulsiveness, emotion stability and clinical characteristics of addiction severity including

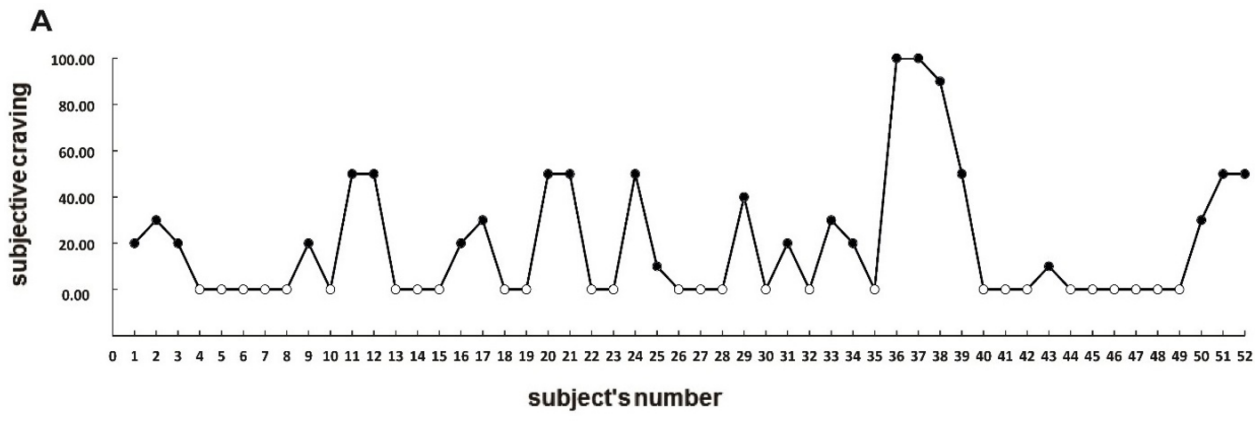

B
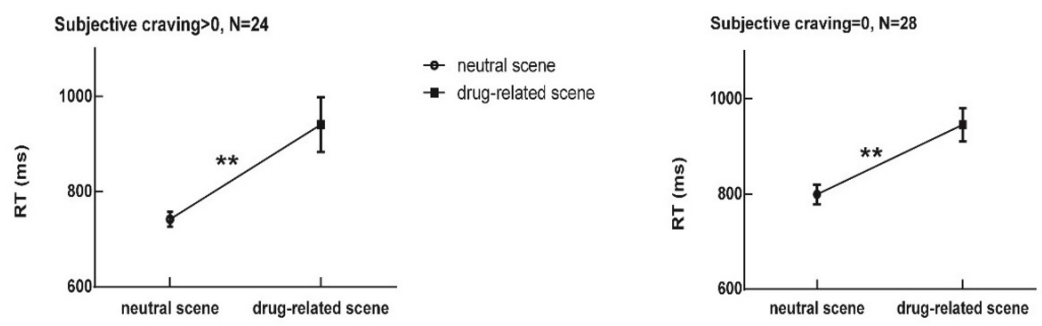

Error Bars: S.E.

Figure 3 Data of all subjects in the subjective craving scale ( $\mathrm{N}=52 ; \mathrm{A})$ and reaction time (RT) data in two groups (zero craving, non-zero craving) for each condition (neutral and drug-related situations) in the visual probe task (B). It is notable that methamphetamine users with non-zero craving $(\mathrm{N}=24)$ and zero-craving $(\mathrm{N}=28)$ both showed a significant attention bias, of a similar size $(p=0.373)$, to drug-related cues $\left(p_{s}<0.001\right)$. 
Table 1 Demographic and clinical characteristics of methamphetamine dependents with zero and non-zero craving reports

\begin{tabular}{|c|c|c|c|c|c|c|c|}
\hline & \multicolumn{2}{|c|}{$\begin{array}{l}\text { Zero craving } \\
(\mathrm{N}=\mathbf{2 8})\end{array}$} & \multicolumn{2}{|c|}{$\begin{array}{l}\text { Non-zero craving } \\
(\mathrm{N}=24)\end{array}$} & \multirow{2}{*}{$\begin{array}{l}\text { Statistical } \\
\text { analysis } \\
t \\
\end{array}$} & \multirow[t]{2}{*}{ df } & \multirow[b]{2}{*}{$P$ values } \\
\hline & Mean & SD & Mean & SD & & & \\
\hline Age & 36.75 & 8.69 & 34.13 & 7.46 & 1.158 & 50 & 0.252 \\
\hline BIS & 60.25 & 8.84 & 63.21 & 8.01 & -1.256 & 50 & 0.215 \\
\hline Emotional stability & 32.11 & 8.19 & 32.92 & 10.26 & -0.316 & 50 & 0.753 \\
\hline Drink & 1.46 & 0.51 & 1.46 & 0.51 & 0.042 & 50 & 0.967 \\
\hline Smoke & 1 & 0 & 1 & 0 & & & \\
\hline History & 4.59 & 3.11 & 4.5 & 2.25 & 0.117 & 50 & 0.907 \\
\hline Maximum & 0.61 & 0.61 & 0.69 & 0.42 & -0.523 & 50 & 0.603 \\
\hline Weekly amount & 1.92 & 2.59 & 2.12 & 1.56 & -0.334 & 50 & 0.74 \\
\hline
\end{tabular}

BIS, Barratt Impulsiveness Scale.

MA use duration, maximum amount and weekly amount (see table 1).

The other 24 participants reported a craving score above zero (mean $(\mathrm{SD})=41.25(25.59))$. The mean RTs (only from trials with correct responses) are shown in table 2. We performed an ANOVA of RTs with background scenes (two scenes: neutral, drug-related) as the repeated factor. The results showed a significant attention bias to drug-related scenes $($ mean $($ neutral $)=742(75.77)$ ms; mean (drug) $=941 \quad(279.25) \quad \mathrm{ms} ; \mathrm{F}(1,23)=16.76$, $p<0.001, \eta_{\mathrm{p}}{ }^{2}=0.42$; see figure $\left.2 \mathrm{~B}\right)$. In addition, the subjects who reported zero (see figure $3 \mathrm{~B}$ ) in subjective craving scale, however, still showed a significant attention bias to drug-related situations in the visual probe test $($ mean $($ neutral $)=799.21 \quad(109.32) ;$ mean $($ drug $)=945.50$ (183.73); $\left.\mathrm{F}(1,27)=18.14, p<0.001, \eta_{\mathrm{p}}^{2}=0.40\right)$.

Furthermore, the independent-samples t-test showed that the magnitude of attention bias to drug-related scenes was similar between users who rated zero and non-zero in cue-induced craving evaluation ( $\mathrm{t}(50)=-0.89, p=0.373)$.

\section{Relationship among craving, attention bias and addiction severity}

Pearson's product-moment correlation (see figure 4) was used to assess the relationship between subjective craving score, attention bias and addiction severity. The magnitude of the RT differences between drug-related and neutral conditions was used as the drug-related attention bias measure. The results (see table 3) showed that the attention bias measure was significantly correlated with all the clinical indexes related to addiction severity, involving MA use duration $(\mathrm{r}=0.336, p=0.015)$, maximum $(\mathrm{r}=0.388$, $p=0.005)$ and weekly amount of MA use $(\mathrm{r}=0.390, p=0.004)$. In contrast, there was no significant correlation between subjective craving score and drug use duration ( $\mathrm{r}=-0.001$, $p=0.996)$, maximum amount $(\mathrm{r}=0.148, p=0.295)$ or weekly amount of MA use $(\mathrm{r}=0.107, p=0.449)$.

\section{DISCUSSION}

\section{Main findings}

Previous studies of addiction intervention mostly focused on reducing cue-induced subjective craving in drug users. However, subjective craving rating is susceptible to quite a few obscuring factors, ${ }^{18} 19$ such as self-report bias, and is easily subject to conscious self-control due to sociocultural influences. In addition, it is common that addicted persons fail to report cue-induced craving. ${ }^{20}$ In this study, we consistently found that more than half of the MA users reported no cue-elicited craving, but they showed a significant attention bias to MA-related scenes in the modified visual probe task. Attention bias for drug-related cues, an information processing bias for drug-related stimuli, has been reported to result in craving and substance use. ${ }^{21}$ In the current study, we directly compared the results between self-reported craving and RT delay for drug-related cues, but we failed to observe the consistency between attentional bias and subjective craving.

Table 2 Reaction time data in two groups (zero craving, non-zero craving) for neutral and drug-related conditions in the visual probe task

\begin{tabular}{lllll}
\hline & Neutral scene & Drug-related scene & $\boldsymbol{F}$ & \multicolumn{1}{c}{ P values } \\
\hline $\begin{array}{l}\text { Subjects with zero craving } \\
(\mathrm{N}=28)\end{array}$ & $799.21(109.32)$ & $945.50(183.73)$ & 18.14 & $<0.001^{* * *}$ \\
$\begin{array}{l}\text { Subjects with non-zero craving } \\
(\mathrm{N}=24)\end{array}$ & $742.03(75.77)$ & $940.68(279.25)$ & 16.76 & $<0.001^{\star \star *}$
\end{tabular}

Mean(SD)

${ }^{*} p<0.05 ;{ }^{* \star} p<0.01 ;{ }^{* \star *} p<0.001$. 
A
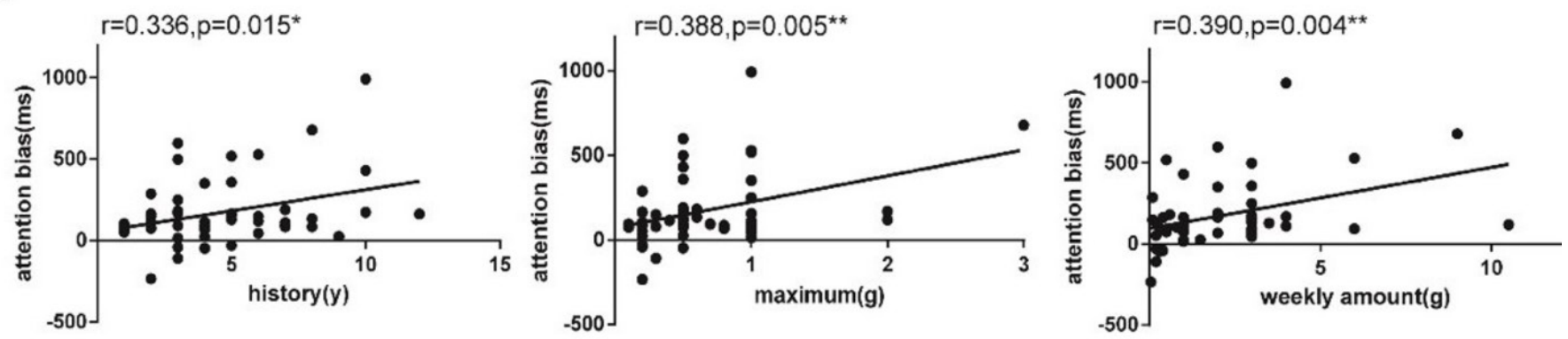

B
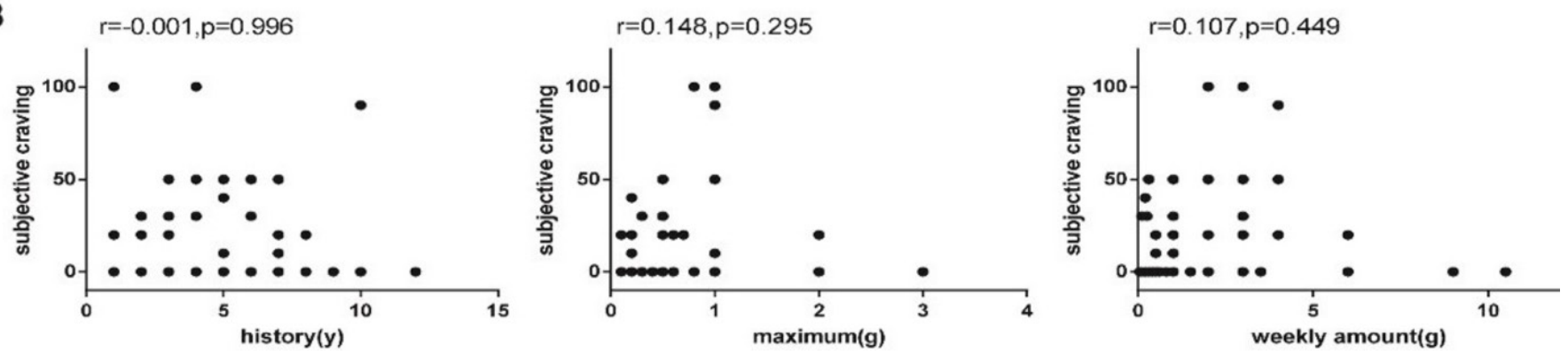

Figure 4 Association between the attention bias measure and addiction severity in methamphetamine use duration (history), maximum amount (one time) and weekly amount (A); and the association between subjective craving and addiction severity (B).

In addition, attention bias to drug cues was strongly correlated with MA use duration, and maximum and weekly amount of MA use, which are central indexes of addiction severity. ${ }^{22}$ However, the positive correlation was absent between subjective craving score and all the three clinical indexes of MA use disorder used in this study. It prompts that attentional bias test may be applied as a more reliable indicator than rated subjective craving in future addiction studies.

At present, there is evidence with other stimulant drugs ${ }^{23}$ but not MA, that interventions aimed at manipulating attention biases do influence future drug use..$^{24} \mathrm{In}$ the current study, our findings further our understanding of attentional bias to MA-related cues in MA use disorder. Attention paid to drug-related cues could distract individuals from effective therapies and prohibit them from the employment of abstinence-oriented coping skills. Measurement of MA-related attention bias is of high clinical importance because of their close relation with addiction severity, indicated by the current correlation analyses.

\section{Limitations}

Several limitations need to be acknowledged. First, we used MA use duration, maximum amount and weekly amount to represent addiction severity. However, these three indexes may only represent addiction severity in part. There are multiple methods to assess addiction severity. For example, McLellan and colleagues ${ }^{22}$ invented the Addiction Severity Index to measure the severity of drug use disorder. However, this instrument gathers information on several addictive areas that participants experienced within the last 30 days. In the current study, we conducted the experiment in Nanjing Compulsory Rehabilitation Center, and all the participants were in compulsory abstinence from drug use for more than 1 month. Thus, instruments that assess addiction severity like this may be unfit for measuring addiction severity in our study. Future studies are still needed to establish standard and recognised instruments to assess addictive severity of MA subjects in compulsory detoxification institutes. Second, subjective craving is susceptible to social approval, especially when measured in a compulsory rehabilitation centre. We did not assess craving before picture presentation, based on the consideration that repeatedly measuring craving may enhance demand effect, which potentially contaminates the true cue-induced craving. However, we cannot assure that this is cue-induced craving because pretest craving was lacking. Third, in the current

Table 3 Correlation between index of two measures and addiction severity

\begin{tabular}{|c|c|c|c|c|c|c|}
\hline & \multicolumn{2}{|c|}{ History } & \multicolumn{2}{|c|}{ Maximum } & \multicolumn{2}{|c|}{ Weekly amount } \\
\hline & $r$ & $P$ values & $r$ & $P$ values & $r$ & $P$ values \\
\hline Attention bias & 0.336 & $0.015^{\star \star}$ & 0.388 & $0.005^{\star \star}$ & 0.390 & $0.004^{* *}$ \\
\hline Subjective craving & -0.001 & 0.996 & 0.148 & 0.295 & 0.107 & 0.449 \\
\hline
\end{tabular}


study, we used six MA-related pictures to induce subjective craving, which may be too short to induce intense craving. This may also explain why a large portion of subjects rated zero in their craving report. Nonetheless, given the robust attention bias effect in these zero-craving subjects, this explanation, again, suggests that attention bias test is a more sensitive index than craving report in assessing addictive severity. Lastly, MA-related pictures used in subjective craving paradigm and visual probe task were not standardised and recognised. Future studies are still needed to establish unified and effective stimulus datasets to induce craving.

\section{Implications}

On the one hand, future studies need to examine electrophysiological correlates of attention bias for MA use scenarios. In addition, attention bias tasks need to be performed during fMRI scan to find its neural underpinnings. On the other hand, the results of this study demonstrated a dissociation between the attentional bias and subjective craving, and we found a predictive role of attention bias for addiction severity, more specifically, in MA use disorder, which may contribute to the clinical use of attentional bias. Future studies should also explore why attention bias serves as a more reliable indicator of addiction severity than experiential craving.

Contributors QL contributed to the experiment conduction, data analysis, and manuscript preparation. TY contributed to the manuscript revision. JYu contributed to study design, data analysis, manuscript writing and supervised the whole project. $\mathrm{XC}$ contributed to the data collection and experiment conduction. HH contributed to the data collection. JYa contributed to the data analysis.

Funding This study was funded by the National Natural Science Foundation of China (grant no. 31871103; 31671164).

Competing interests None declared.

Patient consent for publication Obtained.

Ethics approval This study was approved by the Ethics Committee of Southwest University in China.

Provenance and peer review Not commissioned; externally peer reviewed.

Data sharing statement № additional data are available.

Open access This is an open access article distributed in accordance with the Creative Commons Attribution Non Commercial (CC BY-NC 4.0) license, which permits others to distribute, remix, adapt, build upon this work non-commercially, and license their derivative works on different terms, provided the original work is properly cited, appropriate credit is given, any changes made indicated, and the use is non-commercial. See: http://creativecommons.org/licenses/by-nc/4.0/.

\section{REFERENCES}

1 Wang D, Zhou C, Chang YK. Acute exercise ameliorates craving and inhibitory deficits in methamphetamine: an ERP study. Physiol Behav 2015;147:38-46.
2 Meyer JS. 3,4-Methylenedioxymethamphetamine (MDMA): current perspectives. Subst Abuse Rehabil 2013;4:83-99.

3 Chen YC, Chen CK, Wang LJ. Predictors of relapse and dropout during a 12-week relapse prevention program for methamphetamine users. J Psychoactive Drugs 2015;47:317-24.

4 Ogai Y, Haraguchi A, Kondo A, et al. Development and validation of the Stimulant Relapse Risk Scale for drug abusers in Japan. Drug Alcohol Depend 2007;88:174-81.

5 Perry CJ, Zbukvic I, Kim JH, et al. Role of cues and contexts on drug-seeking behaviour. Br J Pharmacol 2014;171:4636-72.

6 Enokibara M, Trevizol A, Shiozawa P, et al. Establishing an effective TMS protocol for craving in substance addiction: is it possible? Am J Addict 2016;25:28-30.

7 Shen Y, Cao X, Tan T, et al. 10-Hz repetitive transcranial magnetic stimulation of the left dorsolateral prefrontal cortex reduces heroin cue craving in long-term addicts. Biol Psychiatry 2016;80:e13-14.

8 Velligan DI, Wang M, Diamond P, et al. Relationships among subjective and objective measures of adherence to oral antipsychotic medications. Psychiatr Serv 2007;58:1187-92.

9 Tiffany ST. A cognitive model of drug urges and drug-use behavior: role of automatic and nonautomatic processes. Psychol Rev 1990;97:147-68.

10 Gardini S, Caffarra P, Venneri A. Decreased drug-cue-induced attentional bias in individuals with treated and untreated drug dependence. Acta Neuropsychiatr 2009;21:179-85.

11 Field M, Cox WM. Attentional bias in addictive behaviors: a review of its development, causes, and consequences. Drug Alcohol Depend 2008;97:1-20.

12 Soleimannejad M, Tehrani-Doost M, Khorrami A, et al. Evaluation of attention bias in morphine and methamphetamine abusers towards emotional scenes during early abstinence: an eye-tracking study. Basic Clin Neurosci 2015;6:223-30.

13 Nejati M, Nejati V, Mohammadi MR. Selective attention and drug related attention bias in methadone maintenance patients. Acta Med Iran 2011;49:814-7.

14 Hester R, Dixon V, Garavan H. A consistent attentional bias for drug-related material in active cocaine users across word and picture versions of the emotional Stroop task. Drug Alcohol Depend 2006;81:251-7.

15 Cox WM, Fadardi JS, Pothos EM. The Addiction-Stroop test: theoretical considerations and procedural recommendations. Psychol Bull 2006;132:443-76.

16 Ehrman RN, Robbins SJ, Bromwell MA, et al. Comparing attentional bias to smoking cues in current smokers, former smokers, and non-smokers using a dot-probe task. Drug Alcohol Depend 2002;67:185-91.

17 Winters KC, Martin CS, Chung T. Substance use disorders in DSM-V when applied to adolescents. Addiction 2011;106:882-4.

18 Sayette MA, Shiffman S, Tiffany ST, et al. The measurement of drug craving. Addiction 2000;95:189-210.

19 Rosenberg $\mathrm{H}$. Clinical and laboratory assessment of the subjective experience of drug craving. Clin Psychol Rev 2009;29:519-34.

20 Avants SK, Margolin A, Kosten TR, et al. Differences between responders and nonresponders to cocaine cues in the laboratory. Addict Behav 1995;20:215-24.

21 Waters AJ, Marhe R, Franken IH. Attentional bias to drug cues is elevated before and during temptations to use heroin and cocaine. Psychopharmacology 2012;219:909-21.

22 McLellan AT, Luborsky L, Woody GE, et al. An improved diagnostic evaluation instrument for substance abuse patients. The Addiction Severity Index. J Nerv Ment Dis 1980;168:26-33.

23 Hogarth L, Dickinson A, Janowski M, et al. The role of attentional bias in mediating human drug-seeking behaviour. Psychopharmacology 2008;201:29-41.

24 Field M, Marhe R, Franken IHA. The clinical relevance of attentional bias in substance use disorders. CNS Spectr 2014;19:225-30. 
Qiongdan Liang, a first year PhD student in Tsinghua University, major in psychology. She got bachelor's degree in Shaanxi Normal University and a master's degree in South West University (China). Her research interests include drug addiction and behavioral inhibition. 